\title{
EL OBTENTOR VEGETAL Y EL PRODUCTOR: UNA APROXIMACIÓN DESDE UN PUNTO DE VISTA PRÁCTICO
}

\author{
THE VEGETABLE BREEDER AND THE PRODUCER: AN \\ APPROACH FROM A PRACTICAL PERSPECTIVE
}

\section{O OBTENTOR VEGETAL E O PRODUTOR: UMA APROXIMAÇÃO DESDE UM PONTO DE VISTA PRÁTICO}

\author{
ELISA MARÍA MARTÍNEZ MARURI
}

RECIBIDO: $30 / 10 / 2020$

ACEPTADO: $19 / 11 / 2020$

\begin{abstract}
RESUMEN: Hay varios factores que han generado que en nuestro país se le dé cada vez más importancia a las creaciones intelectuales y en particular a las creaciones intelectuales derivadas de la biotecnología. De esta manera, es importante comprender cuál es el rol que ocupan las distintas personas que intervienen en estas creaciones (nuevas variedades vegetales) y en su posterior comercialización, así como en su vinculación contractual. A su vez, estos actores (obtentor vegetal y productor) detentan distintos derechos sobre estas variedades vegetales: el obtentor tiene la protección legal sobre estas variedades y el productor abona un canon para poder realizar multiplicaciones y eventualmente nuevas variedades y luego comercializarlo en el mercado. Todo lo anterior debe regularse estrictamente en un contrato de valor tecnológico, siendo INASE el instituto regulador y URUPOV, la Asociación Civil que interviene en nombre de los obtentores para fiscalizar el cumplimiento de las obligaciones contractuales.
\end{abstract}

PALABRAS CLAVE: Obtentor vegetal, variedades vegetales, cultivar, productor, INASE, URUPOV.

ABSTRACT: Intellectual creations -and specially those connected to biotechnologyis an area that in our country has been given importance, due to several factors. Hence, it is important to understand which is the role that the people who intervenes in these creations (plant varieties) play, as well as its trading and contractual relationship. Also, these parties (vegetable breeder and producer) are entitled to different rights over these varieties: the breeder's creation are legally protected and the producer has to pay to the breeder a fee for the multiplication of the varieties and eventually for producing new varieties from those and trading them. All of the above must be strictly foreseen in a te-

1 Abogada egresada de la Universidad de la República. Asociada en Dentons Jiménez de Arechaga. ORCID ID: https://orcid.org/0000-0002-9494-9510. elisa.martinez@dentons.com 
chnological value agreement, being the Seeds National Office the regulatory entity and the Uruguayan Association for the protection of plant varieties that intervenes on behalf of vegetable breeders to control the enforcement of the agreement.

KEY WORDS: Vegetable breeder, plant varieties, cultivar, producer, INASE, URUPOV.

RESUMO: São vários os fatores que têm gerado que em nosso país se dê cada vez mais importância às criações intelectuais, em particular às criações intelectuais derivadas da biotecnologia. Desta forma, é importante compreender qual é o papel que ocupam as diferentes pessoas que intervêm nestas criações (novas variedades vegetais) e na sua posterior comercialização, bem como na sua vinculação contratual. Por sua vez, estes agentes (obtentor vegetal e produtor) detêm diferentes direitos sobre estas variedades vegetais: o obtentor tem a proteção legal sobre estas variedades e o produtor paga uma taxa para poder efetuar multiplicações e, eventualmente, novas variedades e pela sua comercialização no mercado. Também deve ser estritamente regularizado em um contrato de valor tecnológico, sendo o Instituto Nacional de Sementes do Uruguai (INASE) o regulador, e a Associação Civil Uruguaia para a Proteção dos Obtentores Vegetais (URUPOV) a que intervém em nome dos obtentores para fiscalizar o cumprimento das obrigações contratuais.

PALAVRAS - CHAVE: Obtentor vegetal, variedades vegetais, cultivar, produtor, INASE, URUPOV.

\section{Introducción}

En las últimas décadas y a nivel global, se han dictado leyes y reglamentaciones a fin de proteger la propiedad intelectual de la que son titulares -o pretenden serlo- las personas físicas y/o jurídicas. Así, por ejemplo, se ha regulado la protección de los derechos marcarios, de las patentes (de invención, modelos de utilidad y diseños industriales), de los derechos de autor y del derecho de imagen. Entre ellas, encontramos -dentro del ámbito de la biotecnología- la protección de las obtenciones vegetales, una protección intelectual sui generis, basada en el Convenio Internacional para la Protección de las Obtenciones Vegetales ("Convenio UPOV") que fuera suscrito en París el 2 de diciembre de 1961 y modificado por actas adicionales firmadas en Ginebra el 10 de noviembre de 1972 y el 23 de octubre de 1978. Uruguay forma parte del Convenio UPOV desde el año 1994 en función de la aprobación de la Ley No. 16.580 del 21 de setiembre de 1994, optándose por el sistema de Derechos de Obtentor como único sistema de propiedad intelectual aplicable a las nuevas variedades vegetales. A su vez, en el año 1997 se aprueba la Ley de Semillas No. 16.811 de fecha 21 de febrero de 1997 la que fuera modificada por la Ley 18.467 del 27 de febrero de 2009 (la "Ley de Semillas"), y posteriormente los Decretos reglamentarios No. 104/997 del 02 de abril de 1997 y 438/004 de fecha 16 de diciembre de 2004², disponiéndose expresamente que, para que los cultivares estén protegidos por este régimen deben cumplir con los requisitos dispuestos en el artículo 69 de la Ley de Semillas ${ }^{3}$.

2 Ibarra, M., "La protección de las obtenciones vegetales en Uruguay", disponible en https://www.inase.uy/files/ docse484d6c7112aefb6.pdf. Fecha de última visita 27 de octubre de 2020.

3 Bugallo Montaño, Beatriz; "Propiedad intelectual”; FCU; Montevideo, 2006; pág.484-485. 
En los últimos años, y particularmente en nuestro país, la protección intelectual de los cultivares ha cobrado cada vez mayor trascendencia, particularmente por dos factores: (i) la dependencia de la economía del campo y particularmente de la agricultura, lo que ha llevado a que se apoye por el Estado y por inversores privados el desarrollo de esta área transformando la agricultura tradicional en una agricultura comercial y que prioriza cultivos de alta productividad, justamente por el crecimiento de la población que derivó en un aumento de la demanda de alimentos; y (ii) a raíz de este crecimiento de la población es que se ha potenciado la necesidad de alterar y mejorar los alimentos, estando a su vez ligado a la preponderancia de la biotecnología y de la modernización de todas las creaciones intelectuales.

Este tema a su vez se vio potenciado con la aprobación de la Ley de Regulación y Control del Cannabis No.19.172 del 13 de diciembre de 2013 (la "Ley de Cannabis"), por medio de la cual se legalizó el uso de cannabis con fines recreativos, regulándolo en forma conjunta y sistemática con el uso para fines de investigación y medicinal - que ya se encontraba previsto por la legislación anterior, lo que atrajo a inversores extranjeros para desarrollar y explotar el cultivo de cannabis en nuestro país.

Dentro del tema de los cultivares existen distintos aspectos que merecen ser estudiados por la relevancia que tienen y el interés que generan en la materia, como ser: la regulación normativa, la forma de protección de los derechos de propiedad intelectual de estas creaciones vegetales, los registros existentes en el Instituto Nacional de Semillas ("INASE"), los actores relevantes en la producción y comercialización y su relacionamiento contractual, y, vinculado con todo lo anterior, la creación de la Asociación Uruguaya para la Protección de los Obtentores Vegetales ("URUPOV") que controla que no se infrinjan derechos de propiedad intelectual de los obtentores vegetales.

De esta forma, en tanto hay una ascendiente importancia de la protección de las creaciones intelectuales y su fiscalización, para evitar acciones ilegítimas de terceros que atenten contra los derechos de propiedad intelectual es que se profundizará debajo sobre los últimos tres elementos mencionados, esto es: (i) los actores relevantes en la obtención y comercialización de los cultivares: el obtentor vegetal, el productor de semillas y el agricultor; (ii) los acuerdos de valor tecnológico; y (iii) el rol de URUPOV y de INASE en el control del cumplimiento de los derechos de propiedad intelectual de los que son titulares los obtentores vegetales.

En particular, se analizará: (i) si con la firma de los contratos de valor tecnológico entre el obtentor y el productor se puede evitar la infracción de los derechos de propiedad intelectual del obtentor; (ii) si con una fiscalización rigurosa de INASE y URUPOV se pueden evitar en forma exitosa las infracciones; y (iii) cuáles son las dificultades que se pueden enfrentar a la hora de fiscalizar.

\section{Desarrollo}

\subsection{El obtentor vegetal, el productor de semillas y el agricultor.}

Las obtenciones vegetales, variedades vegetales o cultivares son, según el artículo 82 numeral tercero de la Ley de Semillas, "un conjunto de plantas cultivadas que se distingue de 
las demás de su especie por cualquier característica (morfológica, fisiológica, citológica, química $u$ otras) y que al reproducirse sexuada o asexuadamente mantienen las características que le son propias." En concreto, las variedades vegetales o cultivares se van encontrando a partir de la modificación genética de los propágulos (que son las partes de la planta que pueden originar nuevos ejemplares, como las semillas, las raíces, los esquejes, etc.), siendo las semillas, el mecanismo más común de propagación de las plantas.

Para clarificar con un ejemplo, los genetistas pueden tomar como punto de partida la semilla de trigo seleccionándolas de acuerdo con las aptitudes que quieren conseguir (aptitud panadera, gluten, proteína, o cualquier otra función para lograr su mejoramiento en algún aspecto concreto). Ahí, al modificarlas genéticamente, van a existir distintos cultivares dentro de la semilla de trigo, un cultivar que brindará más gluten u otro que va a tener más aptitud panadera, etc.; dependiendo de cómo se realicen esas alteraciones genéticas. A veces los obtentores simplemente buscan mejorar las características de los cultivares para que resistan ciertas condiciones climáticas y no se eche a perder la cosecha. Tomemos como ejemplo el caso del maíz, que históricamente no era un cultivo adaptado al clima de los Países Bajos y en virtud del trabajo de los obtentores vegetales, a partir del año 1970, los agricultores han podido cultivar nuevas variedades del maíz que se adaptan y sobreviven a las condiciones climáticas de los Países Bajos ${ }^{4}$

Así, los obtentores vegetales realizan inversiones en investigación y desarrollo para obtener variedades de mayor rendimiento y estabilidad de producción, incorporando tecnologías de resistencia a enfermedades, insectos o herbicidas y cualidades agronómicas que favorecen una mayor rentabilidad y sustentabilidad en la producción de las variedades ${ }^{5}$.

Como se comentó antes, para que los cultivares estén protegidos por este régimen deben cumplir con los requisitos dispuestos en el artículo 69 de la Ley de Semillas ${ }^{6}$ y el titular de la obtención vegetal o cultivar será quien figure inscripto ante INASE (en el Registro de Propiedad de Cultivares para gozar de los derechos y facultades correspondientes al derecho de dominio, y en el Registro Nacional de Cultivares para poder comercializarlo).

En este contexto, es menester diferenciar al obtentor vegetal del productor, especialmente en el vínculo contractual por los negocios de semillas y los derechos que detenta cada uno sobre las variedades vegetales.

\footnotetext{
4 UPOV, Seminario sobre la protección de las variedades vegetales y la transferencia de tecnología: beneficios de la colaboración público-privada, Ginebra, Suiza, 2011, pág. 7. Disponible en https://www.upov.int/edocs/pubdocs/es/ upov_pub_357_3.pdf. Fecha de última visita 27 de octubre de 2020

5 http://www.urupov.org.uy/sitio/html/valorTecnologico. Última fecha de visita: 15 de octubre de 2020.

6 Artículo 69 Ley de Semillas: “Para que un cultivar pueda ser objeto de la protección deberá reunir los siguientes requisitos: A) Ser nuevo (se entiende por tal que no haya sido ofrecido en venta ni comercializado con el consentimiento del creador): i) Dentro de la República, durante un período superior al año inmediatamente anterior a la fecha de presentación de la solicitud de protección. ii) Fuera de la República, durante más de seis años en el caso de vides y árboles o de más de cuatro años en el caso de todas las otras plantas. B) Ser claramente diferenciables de cualquier cultivar cuya existencia sea de conocimiento común en la fecha de presentación de la solicitud de protección, respecto de por lo menos una característica morfológica, fisiológica, citológica, química u otra importante, poco fluctuante y susceptible de ser descrita y reconocida con precisión. C) Ser suficientemente homogéneo en el conjunto de sus caracteres de acuerdo con su sistema de reproducción o multiplicación. D) Permanecer estable en sus caracteres esenciales, o sea que al final de cada ciclo de multiplicación realizado en la forma indicada por su creador mantendrá las características por las que éste lo definió. E) Haber recibido una denominación que sea aceptable para el registro en virtud de lo que establezca la reglamentación".
} 
Por un lado, el obtentor vegetal es aquel que figura inscripto ante INASE, pero en sustancia es aquel (persona física o jurídica como ser la empresa semillerista) que realiza las inversiones en investigación y desarrollo para obtener nuevas variedades, aquellas que -como se comentaba previamente- se busca que cuenten con "mejoras" genéticas mediante la introducción de tecnologías. La calidad de obtentor vegetal -derivado de la debida inscripción de la titularidad ante el Registro de Propiedad de Cultivares en INASE- confiere a éste ciertos derechos exclusivos sobre los cultivares, los que están detallados en el artículo 71 de la Ley de Semillas y son: la introducción al país, la producción con fines comerciales, la puesta a la venta, la comercialización en el país y al extranjero y la donación "de los elementos de reproducción sexuada o de multiplicación vegetativa, en su calidad de tal del cultivar en cuestión".

En esta línea, el artículo del Acta de 1991 del Convenio UPOV sobre el derecho de obtentor (gráfico 8) expone los derechos que tiene un obtentor sobre el material de reproducción o de multiplicación de una variedad protegida; teniendo la opción de decidir quién tiene autorización para cultivar la variedad y en qué condiciones.

Por su parte, el artículo 72 de la Ley de Semillas (en su redacción actual) prevé tres excepciones a los derechos protegidos del obtentor estableciendo que se podrá usar ese cultivar registrado sin derecho a compensación de su tenedor: (i) cuando se use o se venda el producto obtenido de cultivo como materia prima o alimento; (ii) cuando se reserve y siembre semilla para uso propio, pero no para comercializar, lo que se conoce como la "excepción del agricultor" que será profundizado debajo; y (iii) cuando otros creadores lo usen con fines experimentales o como fuente de material genético para la creación de nuevos cultivares, a condición de que el cultivar protegido no sea utilizado en forma repetida y sistemática para la producción comercial de otros cultivares.

Por su parte, el productor que se relaciona contractualmente con el obtentor vegetal suele prestar servicios de diversa naturaleza, entre estos, de investigación, desarrollo, producción, multiplicación (a veces es una primera multiplicación lo que se aclara en el contrato) y comercialización de semillas de distintas variedades (por ejemplo, trigo o soja) que ha obtenido bajo licencia de un obtentor, contando con capacidad técnica y económica suficiente para producir y comercializar determinada semilla.

Este relacionamiento se regula en un contrato denominado "de valor tecnológico" conforme se verá debajo, en el cual se acuerda el pago de un canon del productor al obtentor vegetal por la explotación y / o multiplicación de las semillas respecto de las cuales el obtentor le confiere una licencia.

Como puede verse, la protección legal de los derechos del obtentor vegetal tiene como cometido que éste reciba una remuneración adecuada cuando comercialice el material de reproducción o multiplicación de esas variedades mejoradas. Si no se concediesen derechos exclusivos a los obtentores, se vería en riesgo la posición de estos ya que podría existir un aprovechamiento de terceros, en tanto el material genético que atribuye a las plantas su valor distintivo y comercial es por naturaleza autorreproducible, como la propagación por semilla u otro material de multiplicación como se refirió ut supra. Esta característica genera que las innovaciones que incorporan material biológico sean 
particularmente susceptibles a la explotación ilegítima por terceros sin autorización del obtentor/innovador ${ }^{7}$. Y, en definitiva, esto llevaría a que los obtentores dejaran de invertir en el mejoramiento y por ende al final del día el perjuicio sería para toda la sociedad.

Sin perjuicio de esto, y en línea con lo comentado precedentemente, el Convenio UPOV y el artículo 71 de la Ley de Semillas establecen la "excepción del agricultor" por la cual los actos ejecutados en privado, y sin fines comerciales no entran en el ámbito del derecho de obtentor. Así, en los casos en que la "agricultura de subsistencia" atañe a la reproducción o la multiplicación de una variedad por un agricultor con el fin exclusivo de producir un cultivo alimentario para su propio consumo y el de las personas a su cargo que viven en la misma explotación, los miembros de la UPOV podrán considerar que dicha agricultura queda fuera del alcance del derecho de obtentor (lo que sucede en Uruguay $)^{8}$. Al respecto, la Dra. Bugallo ha expresado que "El fundamento del privilegio del agricultor se encuentra en conceder la posibilidad de uso de la semilla de su propia cosecha para la siembre que él mismo realice en sus propias tierras para la siguiente producción" ${ }^{\prime \prime}$, agregando que esta disposición ha dado lugar a abusos.

\subsection{Los acuerdos de valor tecnológico.}

Como viene de expresarse, el obtentor vegetal invierte para mejorar genéticamente las plantas y crear nuevas variedades que, por sus características mejoradas, pueden ser objeto de protección legal con su registro ante el INASE.

¿Cómo sigue la cadena? Habiendo logrado el desarrollo de estas nuevas variedades vegetales, el obtentor se suele vincular contractualmente con los productores de semillas a través de la firma de contratos de valor tecnológico. En estos contratos el obtentor recupera un porcentaje de la inversión realizada en investigación y desarrollo genético cobrando un canon por la licencia que se confiere para el uso de tales cultivares, lo que se acuerda y estipula justamente en dicho documento, generándose un compromiso de pago por parte del productor hacia el obtentor, por el beneficio de la genética mejorada, para que este continúe generando nuevas variedades. Así, el productor que decide sembrar tales variedades reconoce como "contraprestación" esta tecnología novedosa y adhiere a este sistema, sólo sobre la base de la semilla efectivamente sembrada. El productor deberá abonar al obtentor vegetal en concepto de regalías por el uso y goce de los derechos de propiedad intelectual inherentes a las semillas un importe que en general es el correspondiente a cada variedad por bolsa (de determinada cantidad de $\mathrm{kg}$ ) que contengan esas variedades, las que se exigirá sean semillas certificadas y originales de conformidad con lo preceptuado en la Ley de Semillas.

Aparte del pago de la regalía, el productor también se obliga a divulgar y hacer conocer a sus clientes el sistema de valor tecnológico por las sucesivas multiplicaciones pro-

\footnotetext{
7 Laurence R. Helfer, “Derechos de propiedad intelectual sobre variedades vegetales: una visión de conjunto con opciones para los gobiernos nacionales", Estudio legislativo de la fao en línea $\mathrm{n}^{\circ} .31$, Julio de 2002, pág. 5. disponible en http:/ / www.fao.org/fileadmin/user_upload/legal/docs/lpo31-s.pdf. Última fecha de visita 27 de octubre de 2020.

8 UPOV, Seminario sobre la protección de las variedades vegetales y la transferencia de tecnología: beneficios de la colaboración público-privada, Ginebra, Suiza, 2011, pág. 11. Disponible en https://www.upov.int/edocs/pubdocs/es/ upov_pub_357_3.pdf. Fecha de última visita 27 de octubre de 2020

9 Bugallo Montaño, Beatriz; Ob. Cit. Pág. 489
} 
ducidas a partir de la semilla original provista por el obtentor, debiendo hacer cumplir y respetar este régimen a todos sus clientes y terceros adquirentes.

En el curso de dicha producción, es importante que el obtentor asegure distintos aspectos para que la protección de la propiedad intelectual de sus creaciones no sea fácilmente vulnerada. Para el caso de que el productor subcontrate a un tercero para que realice la producción y/o multiplicación de ese cultivar, el productor deberá informar al obtentor quienes son estos terceros subcontratados y asimismo hacer cumplir a estos los derechos de propiedad intelectual de las tecnologías.

El obtentor deberá asegurar que el productor realice las cosechas -tanto propias como las producidas por terceros- a su debido tiempo, minimizando los daños mecánicos posibles y su calidad física y genética, evitando la mezcla de cultivares durante todo el proceso. Para ello, el obtentor podrá -y con el alcance que quede regulado en el contratorealizar los controles de calidad que considere necesarios para asegurar la pureza física y genética del cultivar, incluyendo verificaciones en la siembra, cosecha, almacenaje y procesado. Así, se podrá prever en el contrato que, de comprobarse la mezcla de variedades, la semilla certificada será rechazada por el obtentor no pudiendo ser destinada a la comercialización como tal, siendo obligatorio su destino a consumo.

Una vez abonado el precio de la semilla certificada, por ejemplo, el productor se convertirá en propietario de la totalidad de la producción de esa semilla certificada, no así de la propiedad intelectual de las variedades registradas por el obtentor en el Registro de Propiedad de Cultivares, ni de las tecnologías propias y/o de terceros en su caso, con lo que deberá pagar al obtentor el precio de la regalía sobre dicha producción.

En general en los contratos de valor tecnológico, es decir, el que se celebra entre el obtentor vegetal y el productor, se dispone que el productor es el responsable frente a los terceros de la calidad de esa semilla certificada que comercializa bajo la marca del obtentor vegetal o bajo su propio nombre, inclusive en cuanto a sus aptitudes de poder germinativo y pureza genética, y que será responsable de los daños y perjuicios provenientes de la comercialización de esta. A su vez, se podrá regular la prohibición de vender las bolsas de semilla procesadas sin el previo análisis de calidad de dicha semilla y aprobación en forma escrita por el obtentor haciéndose el productor pasible y responsable de cualquier daño que pudiese ocasionar a un tercero por no acatar dicho proceder.

Pero ciertamente que es muy dificultoso lograr una trazabilidad en el cumplimiento de estos contratos y de los derechos emergentes de ellos, justamente por la masividad que tienen los cultivos - así se venden lotes de variedades vegetales que luego se siembran, o no y se venden por ejemplo a otro productor cuando esto no está autorizado por contrato- vulnerando así los derechos de propiedad intelectual del obtentor vegetal que confió en un determinado productor para que sea este quien siembre esos cultivares y genere nuevas variedades vegetales.

Además de los controles que realiza INASE y URUPOV (lo que será objeto de estudio del capítulo subsiguiente) ¿existen otras formas de poder forzar ese cumplimiento? El artículo 81 de la Ley de Semillas, prevé expresamente la imposición de una multa 
disponiendo que quien ponga a la venta o comercialice, sin autorización de su titular (léase obtentor), material de reproducción sexual o de multiplicación vegetativa, de cultivares inscriptos en el Registro de Propiedad de Cultivares será castigado con multa equivalente a diez veces el valor de las ventas que haya efectuado. A su vez agrega la responsabilidad civil por los daños generados por dicho uso ilegítimo según las normas generales en la órbita del Derecho Civil. Naturalmente que el obtentor intentará incluir cláusulas penales, las que pueden ya sea limitarse al contenido de la disposición legal o prever algo adicional.

Como cierre de este apartado, es menester mencionar lo preceptuado por el artículo séptimo del Acuerdo sobre los aspectos de los derechos de propiedad intelectual relacionados con el comercio ("ADPIC") ratificado por Uruguay por la Ley No.16.671 de fecha 13 de diciembre de 1994, el que mira la transferencia y difusión de la tecnología como uno de los puntos centrales estableciendo que la protección y la observancia de los derechos de propiedad intelectual deben contribuir con esto en pos del beneficio recíproco de los productores y de los usuarios de conocimientos tecnológicos. Esto se ve potenciado y va ligado a lo preceptuado en el numeral segundo del artículo 66 del ADPIC donde se establece que los países desarrollados ofrecerán a las empresas e instituciones de su territorio incentivos destinados a fomentar y propiciar la transferencia de tecnología a los países en vías de desarrollo, con el fin de que éstos puedan establecer una base tecnológica sólida y viable.

Es decir, existen instrumentos internacionales que llaman la atención sobre este tema y motivan los desarrollos tecnológicos y la transferencia de estos, lo que evidencia la actualidad e importancia de los contratos de valor tecnológico.

\subsection{URUPOV e INASE: la fiscalización en el cumplimiento de los derechos de los obtentores vegetales.}

En materia de fiscalización/control de los derechos de los obtentores vegetales, tenemos en nuestro país, por un lado, la intervención de INASE y por otro lado la participación de URUPOV.

En relación con INASE, el artículo tercero de la Ley de Semillas dispone en sus literales $\mathrm{C}$ y $\mathrm{E}$ respectivamente que este instituto tendrá como objetivos proteger las creaciones y los descubrimientos fitogenéticos, y fiscalizar el cumplimiento de la normativa legal en la materia.

Por otro lado, en diciembre del año 1994 se creó la Asociación Civil Uruguaya para la Protección de los Obtentores Vegetales denominada URUPOV que entre sus fines, tiene los siguientes: (i) defender activamente los intereses y derechos de los obtentores vegetales en todas sus formas y orígenes propendiendo a la aplicación irrestricta de la legislación vigente y su perfeccionamiento, combatiendo las prácticas de producción y comercialización ilícita; y (ii) coadyuvar con las entidades públicas, estatales y no estatales en la fiscalización y control de las semillas, transportadas, procesadas multiplicadas, vendidas u ofrecidas o expuestas, a la venta, comercializadas o transferidas a cualquier título, para determinar si dichas semillas cumplen con los requisitos legales y reglamentarios. 
En definitiva, URUPOV cumpliría un rol de apoyo o colaborador de INASE, que es el instituto que tiene las potestades legales de ejercer el control y fiscalización del comercio de semillas de comunicar, informar y también fiscalizar, controlar y sancionar.

Complementando el capítulo precedente, es de estilo que en los contratos de valor tecnológico el obtentor solicite la inclusión de una cláusula en la que se permita el libre acceso de URUPOV, además del propio obtentor, y/o a quien éstos designen a los campos de cultivo, depósitos y planta acondicionadora del productor, con el objeto de obtener muestras y efectuar todos los controles y verificaciones que razonablemente estimen necesarios.

Según la información on-line de URUPOV, a los efectos de realizar una eficiente fiscalización algunas de las técnicas que implementan son: el manejo de bases de datos, cruzamiento de información, relevamiento de áreas sembradas, de lugares de depósito y almacenaje de semillas; así como el uso de kits de detección de presencia o ausencia de la tecnología intacta en soja y el empleo de imágenes satelitales de alta resolución ${ }^{10}$.

Sin dudas todos los avances en las técnicas de fiscalización son herramientas útiles para disuadir los incumplimientos. Sin embargo, es también un hecho que es mucho más dificultoso tener un control minuto a minuto de la trazabilidad de las ventas/entrega de los cultivares de los obtentores y por ende evitar los incumplimientos de estos derechos, justamente por la naturaleza de estos. Es decir, no dejan de ser cultivares que se siembran en campos lo que denota una masividad que no existe en otras áreas de la propiedad intelectual, como por ejemplo con los incumplimientos de los derechos marcarios que al detectar el uso de la marca es mucho más inmediato y tangible que el caso de la venta de semillas en forma indebida y en contravención al contrato de valor tecnológico.

\subsection{En este contexto, ¿dónde queda el cannabis?}

Si bien los cultivares siempre fueron importantes en la mirada comercial y a nivel político por la relevancia de la agricultura en nuestro país, en los últimos años esto se ha visto fuertemente potenciado por la aprobación de la Ley de Cannabis.

A pesar de no ser éste el eje central del artículo, no se puede dejar de mencionar que, con la aprobación de la mencionada ley, las inversiones en este rubro han aumentado exponencialmente, colocando a Uruguay como actor protagónico en este tema a nivel internacional. Aún así, es menester notar que este boom se puede "frenar" a futuro si Uruguay deja de ser competitivo en cuanto a los costos operativos que insume la producción del cáñamo (cannabis no psicoactivo, cuyo contenido de tetrahidrocannabinol (THC) natural es inferior al 1\% de su volumen) o del cannabis psicoactivo (cuyo contenido de (THC) natural es igual o superior al 1\% de su volumen), en comparación con los países vecinos. Por ello, entre otras cosas, es que se debe -por parte del Estado, en las regulaciones que dicta y por parte de los privados en las inversiones- coadyuvar para promover y facilitar las exportaciones y des obstaculizar las dificultades prácticas especialmente en la producción y comercialización del cannabis.

10 http://www.urupov.org.uy/sitio/html/fiscalizacion. Última fecha de visita 15 de octubre de 2020. 
Vinculado con lo anterior, ya sea en la industrialización de productos finales o en generar variedades/genéticas propias que sean protegibles legalmente, si se cumpliera con las condiciones que se vienen de señalar, Uruguay podría ser un país exportador de paquetes tecnológicos a futuro en este sector (genéticas + know-how). De esta manera, los nuevos inversores en producción de cannabis utilizarán como ventana para lograr genéticas propias el numeral iii) del artículo 72 de la Ley de Semillas (fuente de material genético para la creación de nuevos cultivares, a condición de que el cultivar protegido no sea utilizado en forma repetida y sistemática para la producción comercial de otros cultivares).

De esta forma, según un estudio realizado por Uruguay XXI en mayo del corriente año (2020), la trayectoria de Uruguay (vinculado con la existencia de los registros y la evaluación y medición con respaldo oficial) como multiplicador de genética de soja y maíz lo posicionan adecuadamente para el trabajo en genética de cannabis, ya sea que las empresas se instalen para hacer trabajos de multiplicación o para desarrollar sus propias genéticas en Uruguay. Este estudio también hace notar la importancia que tiene para Uruguay contar con una política de desarrollo de genéticas nacionales de cannabis, lo que debe partir de un relevamiento de genéticas existentes y de un llamado a validación de genéticas de cannabis ${ }^{11}$.

\section{Conclusión}

Como conclusiones generales, se puede señalar:

(i) Que, si bien con la firma de contratos de valor tecnológico se puede lograr disuadir los incumplimientos de los derechos del obtentor por parte del productor y/o terceros, como todo contrato, esto dependerá de la voluntad de la parte obligada y en tal caso se estará a las consecuencias de los incumplimientos contractuales; lo que naturalmente se derivará en responsabilidad civil. Es evidente que, a mayor penalidad y fiscalización, es de esperar un mayor respeto por estos derechos.

(ii) Vinculado con el punto precedente, cuanto más rigurosa sea la intervención de INASE y URUPOV, mayor será la disuasión de los incumplimientos. De todas maneras, esto no implica que sea completamente exitoso ya que, en esta área, el controlador se encuentra con una dificultad adicional que es la masividad que tienen los cultivares; por la naturaleza de estos, es evidentemente más dificultoso hacer una trazabilidad de las sucesivas multiplicaciones y respeto de los derechos de los obtentores vegetales.

Considerando los dichos vertidos previamente, es importante también remarcar a modo de conclusión que la comercialización ilegal (incluso con semilla de dudosa calidad) ocasiona graves perjuicios a los agricultores y a las empresas que invierten en investigación para la búsqueda de nuevas variedades, no contando con garantía para la obtención de resultados justamente por las características de esas semillas. Lo anterior sin dudas podrá redundar también en un perjuicio para el consumidor final, quien con-

11 Uruguay XXI, “Oportunidades de inversión - Cannabis”, mayo 2020, disponible en https:/ /www.uruguayxxi.gub. uy/uploads/informacion/37fbeded8d4e83cb31bf340aee41d1958ee6e3f9.pdf. Última fecha de visita 27 de octubre de 2020. 
sumirá los alimentos con la expectativa de que el alimento cuente con las mejores características y garantías en su producción desde el inicio: esto es, desde la semilla.

Vinculado con lo anterior, podemos mencionar la aprobación de la Ley 19.317 del 18 de febrero de 2015 de Regulación de disposiciones para la promoción de la biotecnología, por la cual se declaró de interés nacional el desarrollo de la Biotecnología y sus aplicaciones como factores fundamentales para la innovación tecnológica, la productividad, la competitividad, el desarrollo sostenible y el bienestar de la población. Una vez más, un instrumento legal nacional que fue aprobado para promover la correcta utilización de la biotecnología que, en definitiva, tiene como último objetivo velar por el interés del consumidor final.

\section{BIBLIOGRAFÍA}

IBARRA, M., "La protección de las obtenciones vegetales en Uruguay”, disponible en https:/ / www.inase.uy/files/docse484d6c7112aefb6.pdf.

BUGALLO MONTAÑO, Beatriz; "Propiedad intelectual"; FCU; Montevideo, 2006; pág.484-485.

LAURENCE R. Helfer, “Derechos de propiedad intelectual sobre variedades vegetales: una visión de conjunto con opciones para los gobiernos nacionales", Estudio legislativo de la fao en línea $n^{\circ} .31$, Julio de 2002, pág. 5. disponible en http:/ / www.fao.org/ fileadmin/user_upload/legal/docs/lpo31-s.pdf.

UPOV, Seminario sobre la protección de las variedades vegetales y la transferencia de tecnología: beneficios de la colaboración público-privada, Ginebra, Suiza, 2011, pág. 11. Disponible en https://www.upov.int/edocs/pubdocs/es/upov_pub_357_3.pdf. Fecha de última visita 27 de octubre de 2020

Uruguay XXI, "Oportunidades de inversión - Cannabis", mayo 2020, disponible en https:/ / www.uruguayxxi.gub.uy/uploads/informacion/37fbeded8d4e83cb31bf340aee41d1958ee6e3f9.pdf.

URUPOV, http:/ / www.urupov.org.uy/sitio/html/valorTecnologico. 